\title{
Clinical and cost-effectiveness of oral sodium bicarbonate therapy for older patients with chronic kidney disease and low-grade acidosis (BiCARB): a pragmatic randomised, double-blind, placebo- controlled trial
}

The BiCARB study group

\begin{abstract}
Background: Chronic kidney disease with metabolic acidosis is common in older people, but the effectiveness of oral sodium bicarbonate therapy in this group is unclear. We tested whether oral sodium bicarbonate provides net health benefit for older people with advanced chronic kidney disease and serum bicarbonate concentrations $<22$ $\mathrm{mmol} / \mathrm{L}$.

Methods: Pragmatic multicentre, parallel group, double-blind, placebo-controlled randomised trial. We recruited adults aged $\geq 60$ years with estimated glomerular filtration rate of $<30 \mathrm{~mL} / \mathrm{min} / 1.73 \mathrm{~m}^{2}$, not receiving dialysis, with serum bicarbonate concentration $<22 \mathrm{mmol} / \mathrm{L}$, from 27 nephrology and geriatric medicine departments in the UK. Participants received oral sodium bicarbonate (up to $3 \mathrm{~g} /$ day) or matching placebo given for up to 2 years, randomised in a 1:1 ratio. The primary outcome was between-group difference in the Short Physical Performance Battery (SPPB) at 12 months, adjusted for baseline values, analysed by intention to treat. Secondary outcomes included generic and disease-specific quality of life (EQ-5D and KDQoL tools), anthropometry, renal function, walk distance, blood pressure, bone and vascular health markers, and incremental cost per quality-adjusted life year gained.

Correspondence: Miles.Witham@newcastle.ac.uk

AGE Research Group, NIHR Newcastle Biomedical Research Centre, Biomedical Research Building, Campus for Ageing and Vitality, Newcastle NE4 5PL, UK

(c) The Author(s). 2020 Open Access This article is licensed under a Creative Commons Attribution 4.0 International License, which permits use, sharing, adaptation, distribution and reproduction in any medium or format, as long as you give appropriate credit to the original author(s) and the source, provide a link to the Creative Commons licence, and indicate if changes were made. The images or other third party material in this article are included in the article's Creative Commons licence, unless indicated otherwise in a credit line to the material. If material is not included in the article's Creative Commons licence and your intended use is not permitted by statutory regulation or exceeds the permitted use, you will need to obtain permission directly from the copyright holder. To view a copy of this licence, visit http://creativecommons.org/licenses/by/4.0/ The Creative Commons Public Domain Dedication waiver (http://creativecommons.org/publicdomain/zero/1.0/) applies to the data made available in this article, unless otherwise stated in a credit line to the data. 


\begin{abstract}
(Continued from previous page)
Results: We randomised 300 participants between May 2013 and February 2017, mean age 74 years, 86 (29\%) female. At 12 months, 116/152 (76\%) participants allocated to bicarbonate and 104/148 (70\%) allocated to placebo were assessed; primary outcome data were available for 187 participants. We found no significant treatment effect for the SPPB: bicarbonate arm 8.3 (SD 2.5) points, placebo arm 8.8 (SD 2.2) and adjusted treatment effect - 0.4 (95\% $\mathrm{Cl}-0.9$ to $0.1, p=0.15)$. We found no significant treatment effect for glomerular filtration rate $\left(0.6 \mathrm{~mL} / \mathrm{min} / 1.73 \mathrm{~m}^{2}\right.$, $95 \% \mathrm{Cl}-0.8$ to $2.0, p=0.39$ ). The bicarbonate arm showed higher costs and lower quality of life as measured by the EQ-5D-3L tool over 1 year ( $£ 564$ [95\% Cl $£ 88$ to $£ 1154]$ ]); placebo dominated bicarbonate under all sensitivity analyses. Adverse events were more frequent in those randomised to bicarbonate (457 versus 400).
\end{abstract}

Conclusions: Oral sodium bicarbonate did not improve physical function or renal function, increased adverse events and is unlikely to be cost-effective for use by the UK NHS for this patient group.

Trial registration: European Clinical Trials Database (2011-005271-16) and ISRCTN09486651; registered 17 February 2012.

Keywords: Sodium bicarbonate, Renal insufficiency, chronic, Acidosis, Randomised controlled trial,

\section{Background}

Chronic kidney disease (CKD) becomes increasingly common with older age, with approximately $2 \%$ of the population aged 70 years and over suffering from advanced (estimated glomerular filtration rate [eGFR] $<30$ $\mathrm{mL} / \mathrm{min} / 1.73 \mathrm{~m}^{2}$ ) chronic kidney disease [1]. Impaired ability to excrete hydrogen ions means that advanced CKD is accompanied by metabolic acidosis in approximately $20 \%$ of cases, with rates higher at lower levels of renal function [2]. Metabolic acidosis has been associated in observational studies with a range of adverse health outcomes in patients with CKD, including worse cardiovascular health, lower bone mineral density and increased fracture risk, impaired muscle function and more rapid progression of kidney disease [3-8]. The extent to which acidosis causes these phenomena remains unclear.

Oral sodium bicarbonate has been used for decades to counteract metabolic acidosis. Few trials have tested whether sodium bicarbonate is effective at preventing adverse outcomes from advanced CKD, and is safe in the context of increased sodium load, as opposed to merely increasing the concentration of circulating bicarbonate. Two recent systematic reviews and metaanalyses of small trials of moderate quality suggested a modest beneficial effect on estimated GFR and serum bicarbonate, an uncertain effect on progression to endstage kidney disease and contrasting effects on blood pressure (no effect in one review, and a small increase in the risk of hypertension in the other), and found no data on the effect of bicarbonate on physical function or quality of life $[9,10]$. The mean age of participants in included trials was young, ranging from 41 to 65 years. Sodium bicarbonate carries risks of gastrointestinal side effects, the large tablets and large number of tablets required are awkward for patients to take long term, and there are concerns that the sodium content might increase blood pressure or circulatory overload. These issues are of particular relevance for older people, who make up the majority of people in the UK with advanced kidney disease and are more likely to suffer side effects due to coexisting multimorbidity and polypharmacy. Current guidelines for the management of chronic kidney disease recommend using oral sodium bicarbonate to treat metabolic acidosis but acknowledge the dearth of evidence in this area $[11,12]$.

A focus on single disease outcomes may not always be appropriate for older people with multimorbidity; improvements in a single organ domain may be counterbalanced by harms in other systems. Older people consistently rank physical function and quality of life as the most important outcomes [13] and measurement of these outcomes allows the impact of an intervention to be integrated across multiple organ systems. The primary objective of the BiCARB trial was to determine whether oral bicarbonate therapy improves physical function compared to placebo in older people with CKD and mild acidosis. The secondary objectives were to assess the effect of bicarbonate supplementation on health-related quality of life, biochemical markers of CKD, bone and vascular health, adverse events and healthcare costs.

\section{Methods}

\section{Study design}

We conducted a parallel group, double-blind, placebocontrolled randomised trial. The trial was designed in response to a commissioning brief issued by the National Institute for Health Research (NIHR) Health Technology Assessment board. We recruited participants from nephrology and geriatric medicine outpatients at 27 UK hospitals. Ethical approval was granted by the East of Scotland NHS Research Ethics Committee (approval 12/ $\mathrm{ES} / 0023)$; the trial was also approved by the UK 
Medicines and Healthcare Regulatory Authority (EudraCT number 2011-005271-16; Clinical Trial Authorisation number 41692/0001/001-0001). The trial was co-sponsored by the University of Dundee and NHS Tayside (Tayside Academic Health Sciences Collaboration). The trial was registered at www.isrctn.com (ISRCTN09486651). The protocol has been published [14].

\section{Participants}

Participants were eligible for inclusion if they were $\geq 60$ years with advanced CKD (estimated GFR $<30 \mathrm{~mL} / \mathrm{min} /$ $1.73 \mathrm{~m}^{2}$ by Modification of Diet in Renal Disease study four variable (MDRD4) equation [15]), not receiving dialysis, with serum bicarbonate concentrations $<22 \mathrm{mmol} /$ L. No lower limit on bicarbonate concentration was stipulated. The MDRD4 equation was used as this was the equation in common use in the UK at the time that the trial was designed. We excluded participants if they were currently taking bicarbonate (such participants could however enter a 3-month washout period, after which they became eligible), had a diagnosis of renal tubular acidosis, were taking a bisphosphonate, were terminally ill, could not give written informed consent, had uncontrolled hypertension (blood pressure $>150 / 90$ despite four or more antihypertensive agents) or decompensated chronic heart failure, were participating in another clinical trial, or were allergic to sodium bicarbonate tablets or lactose (excipient in the tablets). All participants gave written informed consent.

We relaxed the exclusion criteria for the trial part-way through recruitment, both to improve slow recruitment rates, in part influenced by the lack of equipoise amongst clinicians and to better reflect current UK clinical practice. We reduced the lower age limit from 65 to 60 ; we included patients taking calcium acetate or sevelamer; we included patients with blood pressure controlled on home readings even if office blood pressure was high, and we allowed those currently taking bicarbonate to undergo a 3-month washout period with assessment of eligibility at the end of the washout period.

\section{Randomisation and masking}

We randomised participants using an interactive webbased randomisation, drug assignment and inventory management system (TRuST) run by the Health Informatics Centre, University of Dundee. The system was run independently from the research team to preserve allocation concealment. We performed randomisation in a 1:1 ratio, stratified by site, and employed a minimisation algorithm to balance male vs female sex, CKD eGFR category 4 vs category 5 , and age $<75$ years versus $\geq 75$ years. We allocated study medication bottles to participants (one bottle per month) with either $500 \mathrm{mg}$ sodium bicarbonate tablets or matching placebo tablets; we allocated bottles using identification numbers generated by the TRuST randomisation system, and bottles carried no external indication to identify to which trial arm participants were allocated. Participants, researchers and clinical teams and researchers including the statistician remained masked to treatment allocation until after completion of the main trial analysis.

\section{Trial intervention and comparator}

Active and placebo tablets were manufactured and bottled by Legosan AB (Kumla, Sweden). For the first 3 months of participation, we asked participants to take one tablet three times daily (i.e. $500 \mathrm{mg}$ of sodium bicarbonate or placebo three times a day). We measured serum bicarbonate concentration at the 3-month visit to guide dose titration. If bicarbonate was $<22 \mathrm{mmol} / \mathrm{L}$, we asked participants to increase their study medication to two tablets three times a day (i.e. $1 \mathrm{~g}$ of sodium bicarbonate or placebo three times a day). If bicarbonate was $\geq 22 \mathrm{mmol} / \mathrm{L}$, we asked participants to continue taking one tablet three times a day for the remainder of the trial. Although higher doses of bicarbonate have been used in some previous trials [9], we selected this dose to reflect current UK clinical practice in the treatment of acidosis; we judged that higher doses would be poorly tolerated by older people on multiple medications. No trial-specific dietary advice beyond usual care was given, and no specific recommendations on management of low serum bicarbonate concentrations were given to study physicians.

\section{Outcomes}

We measured outcomes at baseline and 3, 6, 12 and 24 months. The primary outcome was the between-group difference in the Short Physical Performance Battery (SPPB) at 12 months, adjusted for baseline values. The SPPB is a 12-point measure of lower limb strength and balance, with higher values denoting better function, that predicts future disability, need for care and death [16-18]. The minimum clinically important difference has been derived for the measure [16].

Secondary outcome measures were generic (EuroQoL EQ-5D-3L) [19] and disease-specific (Kidney Disease Quality of Life) [20] health-related quality of life, anthropometry (weight, mid-arm muscle circumference, triceps skinfold thickness, mid-thigh circumference), physical performance (6-min walk speed, grip strength) and renal function (serum creatinine, cystatin $\mathrm{C}$, and urinary albu$\mathrm{min} /$ creatinine ratio); markers of bone turnover and mineral metabolism (serum calcium, phosphate, bonespecific alkaline phosphatase, tartrate-resistant acid phosphatase 5b, 25-hydroxyvitamin $\mathrm{D}$ and 1,25 dihydroxyvitamin D); vascular health (blood pressure, B-type 
natriuretic peptide and serum cholesterol); and relevant markers, including haemoglobin, thyroid-stimulating hormone and albumin. Originally planned substudies examining arterial stiffness and bone mineral density were discontinued due to very low recruitment rates. We recorded all adverse events, including commencement of renal replacement therapy (defined as the first episode of haemodialysis, peritoneal dialysis or renal transplantation). We recorded falls prospectively using participant-completed fall diaries, and we measured adherence by counting pills taken divided by the number of pills expected to be taken. For the health economic analysis, we collected information on health and social care use using participant-completed questionnaires at follow-up visits, and we combined these data with health-related quality of life measures (EQ-5D-3L and ICEpop CAPability measure for Older people [ICECAP$\mathrm{O}]$ ) and a measure of global life satisfaction to derive the incremental cost per quality-adjusted life year (QALY) gained.

\section{Statistical analysis}

We based the original sample size calculation on the ability to detect a 1-point difference in the primary outcome (SPPB), a difference proposed as the minimum clinically important difference (MCID) by previous investigators [16]. Previous work with older people has shown a standard deviation of 2.6 for the SPPB [21]. To detect a 1-point difference between groups at 12 months with $90 \%$ power given this standard deviation would require 143 participants per group given a two-sided alpha of 0.05 . To ensure that the trial had sufficient power for the key secondary outcome of health-related quality of life, we also estimated the sample size required to detect the MCID for the EQ-5D-3L measure. For the EQ-5D$3 \mathrm{~L}$, we assumed a MCID of 0.074 based on previous data [22]. To detect this change at a two-sided alpha of 0.05 and power of $90 \%$ power, assuming a SD of change of 0.2 as found in our previous studies [23, 24] would require 154 participants per group. Assuming a 10\% loss to follow-up every 6 months (based on previous medication trials in frail older people) [24], we estimated that we would require 380 patients (190 per group) to detect the MCID with $90 \%$ power for the primary outcome and the EQ-5D-3L at 12 months.

We used a prespecified statistical analysis plan. All analyses were by intention to treat using SAS v9.4 (SAS Institute Inc., Cary, NC, USA). We analysed the primary outcome (between-group difference in the SPPB at 12 months) using linear mixed models, adjusted for baseline measurements, minimisation variables (age, sex and CKD category) and a random effect variable for recruitment site. We analysed secondary outcomes using repeated measures mixed models, including all participants and including data from all available timepoints. Models were adjusted for baseline values and the minimisation variables. We conducted time-to-event analyses (time to death, time to commencing renal replacement therapy) using Cox proportional hazards models adjusted for minimisation variables. All participants were included in these analyses, with participants censored at the point of dropout or truncation of follow-up for those not reaching the analysis endpoint before 24 months. For all analyses, we took a two-sided $p$ value of $<0.05$ as significant with no adjustment for multiple testing. For the health economic analysis, we undertook a cost-utility analysis which involved estimation of the incremental costs and incremental effects (QALYs) from a health and social care perspective. We used UK sources for unit cost estimates for items of resource use $[25,26]$ but did not include costs of medications other than bicarbonate. We derived estimates using generalised linear regression modelling, with adjustment for skewed data and for baseline differences in cost, EQ-5D-3L and minimisation variables. We used non-parametric bootstrap methods to calculate confidence intervals around cost and QALY differences. We generated cost-effectiveness acceptability curves to show the probability that bicarbonate therapy was cost-effective for different values of willingness to pay per additional QALY. We conducted a series of sensitivity analyses, using different measures of quality of life to derive QALYs, testing a range of different assumptions on costs and using multiple imputation to account for missing data. Sensitivity analyses included analyses that included renal replacement therapy costs assumed to be incurred after dropout from the trial for those who started renal replacement therapy but then discontinued trial participation.

An independent Data Monitoring Committee (DMC) met every 6 months to review unmasked reports. The DMC examined trial safety, data quality and study conduct and provided advice to the Sponsor, Trial Steering Committee (TSC) and funder on the appropriateness of continuing the trial. No interim efficacy analyses were planned or conducted. The independent TSC recommended closure of recruitment to the trial after 300 participants had been randomised, based on a review of declining recruitment rates and informed by revised sample size calculations that showed that a sample size of 300 had $87 \%$ power to detect a 1-point difference in the primary outcome of the short physical performance battery. The independent TSC also recommended that follow-up be truncated after the final 12-month (primary outcome) visit for the last participant to facilitate earlier dissemination of results. The decision to close the trial to further recruitment was made by the trial funder. 


\section{Results}

We randomised 300 participants into the trial between 1 May 2013 and 28 February 2017. Figure 1 depicts the flow of participants through the trial; the mean length of follow-up per participant was 16.4 months (16.6 (SD 8.9) months in the bicarbonate arm (median 24, IQR 12 to 24 months) and 16.3 (SD 9.4) months in the placebo arm (median 24, IQR 6 to 24 months)). Data for the primary outcome analysis were available for 274 participants at baseline (140 in the bicarbonate arm and 134 in the placebo arm) and for 187 participants at 12 months (97 in the bicarbonate arm and 90 in the placebo arm). One hundred sixty-one participants completed the full 24-month follow-up period. Loss to follow-up was due to a combination of deaths and illness; most participants who commenced dialysis chose to withdraw from the trial due to the added burden of dialytic treatment, although this was not mandated by the protocol. Twentytwo participants had their follow-up truncated due to termination of the trial.

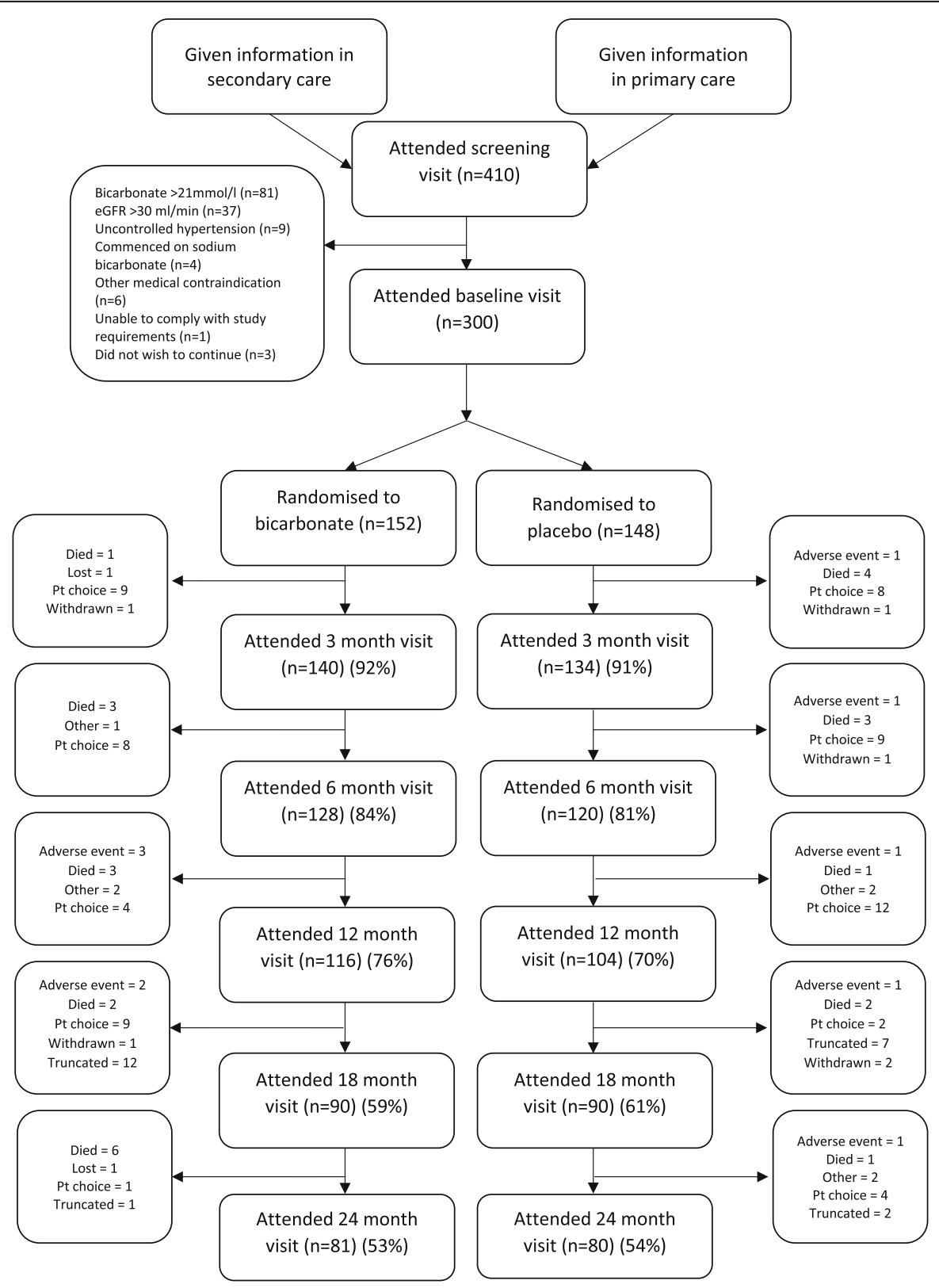

Adverse event $=$ withdrew due to adverse event. Lost $=$ lost to follow up. Pt choice $=$ participant chose to withdraw. Truncated $=$ early study completion due to truncated follow up. Withdrawn = withdrawn by investigator.

Fig. 1 CONSORT diagram for participant flow through the trial 
Baseline details for randomised participants in both arms of the trial are given in Table 1. Only four participants underwent the 3-month washout option prior to randomisation. Adherence by tablet count was moderate: $73 \%$ (95\% CI 67 to 78 ) in the bicarbonate arm and 73\% ( $95 \%$ CI 67 to 80 ) in the placebo arm. Forty-six of 152 participants in the bicarbonate arm had a serum bicarbonate concentration of $<22 \mathrm{mmol} / \mathrm{L}$ and were uptitrated at the 3 -month visit, compared to $83 / 148$ in the placebo arm. A modest but significant increase in serum bicarbonate concentration of $1.7 \mathrm{mmol} / \mathrm{L}$ (95\% CI 1.0 to $2.4, p<0.001$ ) was seen in the intervention arm compared to placebo at 3 months; this difference attenuated with time and was no longer significant by 24 months, as shown in Fig. 2. During the course of the trial, 18 participants in the placebo group stopped taking study medication on the advice of the clinical team in order to start taking prescribed sodium bicarbonate. These individuals were retained in follow-up and analysed as per their initial randomised allocation.

There was no significant between-group difference in the primary outcome (SPPB at 12 months, adjusted for baseline values, age, sex and CKD stage). The adjusted treatment effect was -0.4 points ( $95 \% \mathrm{CI}-0.9$ to $0.1, p=0.15)$ (negative values indicate worse physical performance in the intervention arm); analysis adjusted only for baseline SPPB gave the same result. Multiple imputation to account for missing data gave similar results (adjusted treatment effect -0.3 points, $95 \% \mathrm{CI}-1.0$ to $0.3, p=0.29$ ), and repeated measures analysis across the whole of trial follow-up gave a treatment effect of -0.6 points $(95 \% \mathrm{CI}-1.0$ to $-0.1, p=$ $0.02)$. The participants who were unable to perform the SPPB at 12 months had borderline lower baseline SPPB scores, lower baseline grip strength and lower 6-min walk distance in both the bicarbonate and placebo arms but had similar baseline serum bicarbonate concentrations. Full details are given in Additional File 1.

We conducted prespecified subgroup analyses for the primary outcome by age, sex, baseline eGFR category, baseline serum bicarbonate concentration and baseline SPPB score; results are given in Fig. 3. No significant treatment by subgroup interactions were found. We conducted a further pre-planned subgroup analysis, comparing the primary outcome treatment effect for those with good adherence to study medication (defined a priori as $>80 \%$ ) versus poorer adherence to study medication (defined a priori as $\leq 80 \%$ ). Those with good adherence showed an adjusted treatment effect at 12 months of -0.6 (95\% CI 1.4 to $0.1 ; p=0.07$ ), compared to an adjusted treatment effect of $0.0(95 \% \mathrm{CI}-0.7$ to $0.7 ; p=0.97)$ for those with poorer adherence. The difference in treatment effects was not significant ( $p$ for interaction $=0.27$ ).

Adjusted treatment effects for secondary outcomes are given in Table 2. A total of 66/300 (22\%) of participants commenced dialysis or underwent renal transplantation during the trial, with no difference between the bicarbonate and placebo arms (33 vs $33 ; p=1.0$ ). Time to event analysis showed no significant difference in the risk of commencing renal replacement therapy (HR 1.22, 95\% CI 0.74 to $2.02 ; p=0.43$ ) (values greater than 1 indicate higher risk in the intervention arm), or for reaching a composite outcome of time to either doubling of serum creatinine, a $40 \%$ reduction in eGFR, or commencing renal replacement therapy (HR 1.16, 95\% CI 0.73 to $1.84 ; p=0.53)$. More participants in the bicarbonate arm reported at least one fall than in the placebo arm but this did not reach significance ( 49 vs $39 ; p=0.26$ ); the incident rate in each arm was not significantly different (bicarbonate arm, 0.99 per year [95\% CI 0.61 to 1.38 ]; placebo arm, 0.72 per year [95\% CI 0.25 to 1.19 ]; $p=$ 0.38). Median time to first fall amongst those who fell was shorter in the bicarbonate arm (130 days vs 194 days). Cox proportional hazards modelling of time to first fall, adjusted for age, sex and CKD category, showed a HR of $1.43,95 \%$ CI 0.94 to $2.20, p=0.09$. Fragility fracture numbers were low: $5 / 152$ in the bicarbonate arm and 2/148 in the placebo arm.

Similar numbers of participants in each arm experienced at least one adverse event (131/152 [86.1\%] in the bicarbonate arm vs $132 / 148$ [89.1\%] in the placebo arm; $p=0.38)$. More adverse events were recorded in the bicarbonate arm than in the placebo arm (457 vs 400) with an excess of events in the bicarbonate arm coded under gastrointestinal (45 vs 25), musculoskeletal (28 vs 17 ), cardiac (32 vs 19), nervous (24 vs 12) and respiratory (26 vs 14) systems. Full details are presented in Table 3 . The difference in cardiac events was driven by an excess of myocardial infarction or acute coronary syndrome (10 vs 2 ), and not by a difference in decompensated heart failure (8 vs 10). Twenty-six deaths were recorded during the trial, with similar numbers in the bicarbonate and placebo arms ( 15 vs $11 ; p=0.45)$. Time to event analysis showed no significant difference in the risk of death between groups (HR 1.30, 95\% CI 0.60 to $2.83 ; p=0.51$ ).

\section{Cost-effectiveness analyses}

In unadjusted analysis amongst complete cases, the mean costs per participant over the first 12 months of follow-up were $£ 1234$ amongst the bicarbonate group $(n=97)$ and $£ 807$ amongst the placebo group $(n=79)$. Table 4 shows the adjusted costs and QALYs for each group for complete cases at 12 month and 24 months, and imputed cases with renal replacement costs included. Costs were significantly higher amongst patients who received bicarbonate, and QALYs were significantly lower. The only exception to this was the imputed analysis, where cost differences were no longer significant. The robustness of these analyses was assessed using different acquisition cost estimates for bicarbonate therapy 
Table 1 Baseline characteristics of randomised participants ( $n=$ 300)

\begin{tabular}{|c|c|c|}
\hline & $\begin{array}{l}\text { Sodium bicarbonate } \\
(n=152)\end{array}$ & $\begin{array}{l}\text { Placebo } \\
(n=148)\end{array}$ \\
\hline Mean age (years) (SD) & $73.9(7.6)$ & $74.0(6.6)$ \\
\hline Age 60-64 (\%) & $13(8.6)$ & $13(8.8)$ \\
\hline Age 65-69 (\%) & $44(28.9)$ & $22(14.9)$ \\
\hline Age 70-74 (\%) & $23(15.1)$ & $44(29.7)$ \\
\hline Age 75-79 (\%) & $30(19.7)$ & $37(25.0)$ \\
\hline Age 80-84 (\%) & $32(21.1)$ & $24(16.2)$ \\
\hline Age 85 and over (\%) & $10(6.6)$ & $8(5.4)$ \\
\hline Female sex (\%) & $42(27.6)$ & $44(29.7)$ \\
\hline \multicolumn{3}{|l|}{ Ethnicity } \\
\hline White (\%) & $144(94.7)$ & $143(96.6)$ \\
\hline East Asian (\%) & $0(0)$ & $1(0.7)$ \\
\hline Black (\%) & $1(0.7)$ & $0(0)$ \\
\hline South Asian (\%) & $4(2.6)$ & $2(1.4)$ \\
\hline Hispanic (\%) & $1(0.7)$ & $0(0)$ \\
\hline Other (\%) & $2(1.3)$ & $2(1.4)$ \\
\hline \multicolumn{3}{|l|}{ Cause of renal dysfunction* } \\
\hline Hypertension (\%) & $37(24.3)$ & $40(27.0)$ \\
\hline Diabetes mellitus (\%) & $23(15.1)$ & $23(15.5)$ \\
\hline Glomerulonephritis (\%) & $9(5.9)$ & $11(7.4)$ \\
\hline Polycystic kidney disease (\%) & $11(7.2)$ & $9(6.1)$ \\
\hline Vascular disease (\%) & $19(12.5)$ & $21(14.2)$ \\
\hline Other (\%) & $52(34.2)$ & $63(42.6)$ \\
\hline Not known (\%) & $31(20.4)$ & $22(14.9)$ \\
\hline \multicolumn{3}{|l|}{ Cardiovascular comorbidity } \\
\hline Hypertension (\%) & $135(88.8)$ & $129(87.2)$ \\
\hline Diabetes mellitus (\%) & $54(35.5)$ & $47(31.8)$ \\
\hline Ischaemic heart disease (\%) & $26(17.1)$ & $31(20.9)$ \\
\hline Stroke (\%) & $16(10.5)$ & $12(8.1)$ \\
\hline Heart failure (\%) & $19(12.5)$ & $5(3.4)$ \\
\hline Peripheral vascular disease (\%) & $14(9.2)$ & $10(6.8)$ \\
\hline Previous fragility fracture (\%) & $2(1.3)$ & $5(3.4)$ \\
\hline Mean number of medications (SD) & $8.2(3.7)$ & $7.9(3.3)$ \\
\hline \multicolumn{3}{|l|}{ Medication use: } \\
\hline ACEi/ARB (\%) & $105(69.1)$ & $91(61.5)$ \\
\hline Phosphate binder (\%) & $32(21.1)$ & $28(18.9)$ \\
\hline Activated vitamin D (\%) & $77(50.7)$ & $73(49.3)$ \\
\hline Erythropoietin (\%) & 89 (58.6) & $106(71.6)$ \\
\hline Iron (\%) & $60(39.5)$ & $51(34.5)$ \\
\hline Mean eGFR (mL/min/1.73 m²) (SD) & $19.7(6.5)$ & $18.2(6.4)$ \\
\hline CKD category $5(\%)$ & $34(22.4)$ & $48(32.4)$ \\
\hline $\begin{array}{l}\text { Mean serum bicarbonate }(\mathrm{mmol} / \mathrm{L}) \\
\text { (SD) }\end{array}$ & $20.6(2.6)$ & $20.1(2.5)$ \\
\hline Mean haemoglobin (g/L) (SD) & $115(14)$ & $117(17)$ \\
\hline
\end{tabular}

Table 1 Baseline characteristics of randomised participants ( $n=$ 300) (Continued)

\begin{tabular}{lll}
\hline & $\begin{array}{l}\text { Sodium bicarbonate } \\
(n=152)\end{array}$ & $\begin{array}{l}\text { Placebo } \\
(n=148)\end{array}$ \\
\hline $\begin{array}{l}\text { Mean serum potassium (mmol/L) } \\
\text { (SD) }\end{array}$ & $4.9(0.5)$ & $4.9(0.5)$ \\
$\begin{array}{l}\text { Mean Short physical performance } \\
\text { battery (SD) }\end{array}$ & $8.0(2.4)$ & $8.1(2.2)$ \\
$\begin{array}{l}\text { Mean 6-min walk distance } \\
\text { (m) (SD) }\end{array}$ & $304(134)$ & $317(133)$
\end{tabular}

(m) (SD)

Mean handgrip strength $(\mathrm{kg})(\mathrm{SD})$

\begin{tabular}{|c|c|c|}
\hline Males & $26.6(8.8)$ & $28.0(7.6)$ \\
\hline Females & $15.4(4.8)$ & $15.8(4.4)$ \\
\hline $\begin{array}{l}\text { Mean body mass index }\left(\mathrm{kg} / \mathrm{m}^{2}\right) \\
\text { (SD) }\end{array}$ & $28.9(4.5)$ & $28.3(4.6)$ \\
\hline $\begin{array}{l}\text { Mean mid-arm muscle } \\
\text { circumference }(\mathrm{cm})(\mathrm{SD})\end{array}$ & $24.9(3.6)$ & $24.8(4.0)$ \\
\hline $\begin{array}{l}\text { Mean triceps skinfold } \\
\text { thickness }(\mathrm{mm})(\mathrm{SD})\end{array}$ & $16(8)$ & $17(9)$ \\
\hline $\begin{array}{l}\text { Mean mid-thigh } \\
\text { circumference (cm) (SD) }\end{array}$ & $47.4(7.0)$ & $46.8(7.0)$ \\
\hline Mean EQ-5D-3L (SD) & $0.73(0.22)$ & $0.74(0.24)$ \\
\hline Mean EQ-5D thermometer (SD) & $69(19)$ & $71(19)$ \\
\hline \multicolumn{3}{|l|}{ Mean KDQoL scores } \\
\hline SF36 PCS (SD) & $36(11)$ & $36(11)$ \\
\hline SF36 MCS (SD) & $53(11)$ & $54(9)$ \\
\hline Burden (SD) & $75(26)$ & $75(25)$ \\
\hline Symptoms (SD) & $79(14)$ & $81(12)$ \\
\hline Effects (SD) & $86(14)$ & $87(15)$ \\
\hline $\begin{array}{l}\text { Mean office systolic blood } \\
\text { pressure }(\mathrm{mmHg})(\mathrm{SD})\end{array}$ & $143(18)$ & $143(18)$ \\
\hline $\begin{array}{l}\text { Mean office diastolic blood } \\
\text { pressure }(\mathrm{mmHg})(\mathrm{SD})\end{array}$ & $75(11)$ & $73(10)$ \\
\hline \multicolumn{3}{|c|}{$\begin{array}{l}\text { ACEi angiotensin-converting enzyme inhibitor, } A R B \text { angiotensin receptor } \\
\text { blocker, } C K D \text { chronic kidney disease, } K D Q O L \text { Kidney Disease Quality of Life } \\
\text { questionnaire, SF-36 Short-Form } 36 \text {-Item questionnaire, } P C S \text { physical } \\
\text { component summary, MCS mental component summary, EQ-5D EuroQoL } 5 \\
\text { dimension quality of life questionnaire } \\
\text { *More than one aetiology possible: thus, values sum to }>100 \%\end{array}$} \\
\hline
\end{tabular}

and inpatient stays, together with different estimates of benefit (ICECAP-O measure and global life satisfaction). Figure 4 shows the scatterplot and the associated costeffectiveness acceptability curves for these analyses. Without including renal replacement costs, there is almost zero probability of the intervention being costeffective at conventional thresholds of willingness to pay. With the inclusion of renal replacement costs, the probability that bicarbonate is cost-effective is no higher than $40 \%$, and at the value of $£ 30,000$ per QALY conventionally used in the UK as a cost-effectiveness threshold, the probability is $14 \%$. Across the 24-month follow-up, slightly more participants had at least one EQ-5D measure missing in the placebo group than in the bicarbonate group ( $45 \%$ vs $36 \%$ ) and slightly more participants had 

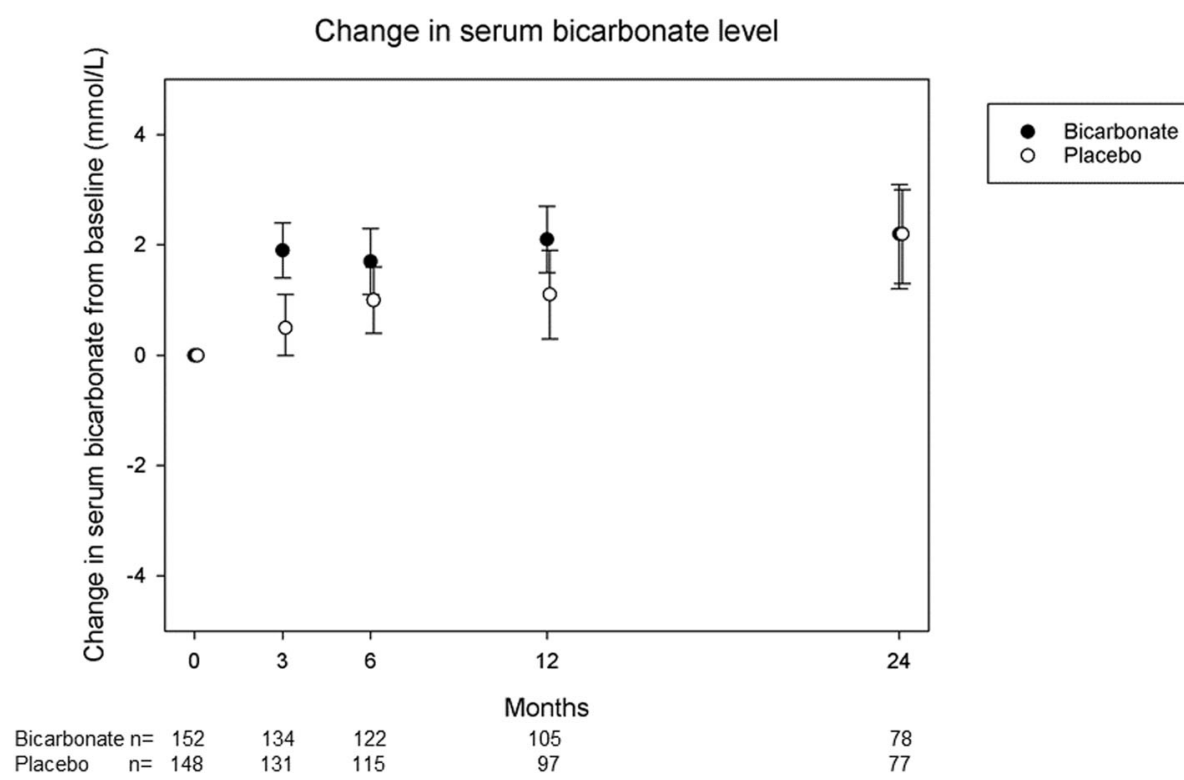

Placebo

Fig. 2 Serum bicarbonate concentrations. Values are mean and 95\% Cl

at least one timepoint with missing costs in the placebo group than the bicarbonate group (36\% vs 31\%). However, the results were also robust to analyses that used multiple imputation for missing values.

\section{Discussion}

\section{Key findings}

Our study is the first to examine the effect of oral bicarbonate therapy on physical function, health-related quality of life and healthcare costs in older people with advanced CKD. In this trial, administration of oral sodium bicarbonate using a dose regime similar to that currently used in UK practice did not improve physical function or quality of life, increased adverse events and had no impact on the rate of progression of CKD compared to placebo in older people with CKD category 4 or 5 and serum bicarbonate concentrations of $<22 \mathrm{mmol} / \mathrm{L}$. Consistent with these findings, health economic analysis showed that bicarbonate was less cost-effective than placebo.

\section{Strengths and weaknesses}

Important strengths of this trial were its large size in comparison to previous trials in this area, the fact that it

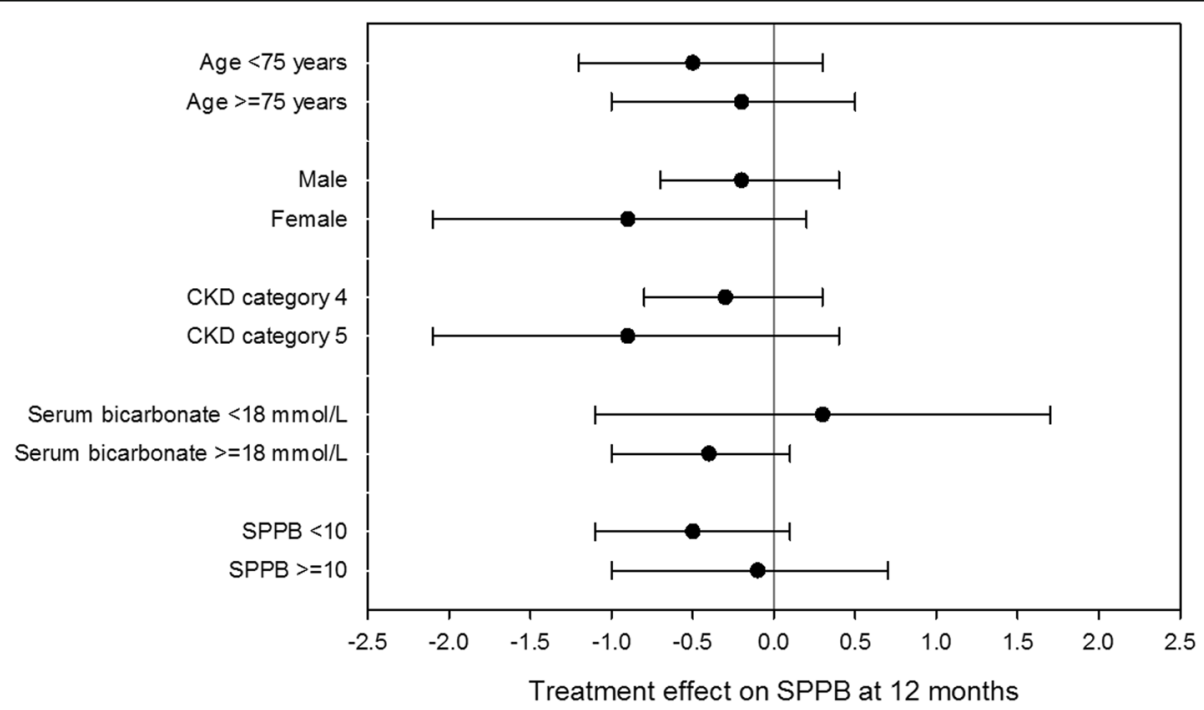

Fig. 3 Subgroup analyses for the primary outcome (Short Physical Performance Battery). Values are mean and $95 \% \mathrm{Cl}$ 
Table 2 Secondary outcomes-adjusted treatment effects (repeated measures analyses using data from all available timepoints, adjusted for age, sex and CKD category)

Treatment effect (bicarbonate- $p$ placebo) $(95 \% \mathrm{Cl})$

Physical function and

anthropometry

$\begin{array}{ll}\text { Six-min walk distance }(\mathrm{m}) & -33(-62 \text { to }-4) \\ \text { Grip strength }(\mathrm{kg}) & -1.5(-2.8 \text { to }-0.2) \\ \text { Weight }(\mathrm{kg}) & 0.2(-2.9 \text { to } 3.4) \\ \begin{array}{l}\text { Mid-arm muscle } \\ \text { circumference }(\mathrm{cm})\end{array} & 0.0(-0.6 \text { to } 0.6) \\ \begin{array}{l}\text { Triceps skinfold thickness } \\ \text { (mm) }\end{array} & -1(-2 \text { to } 1) \\ \begin{array}{l}\text { Mid-thigh circumference } \\ \text { (cm) }\end{array} & 0.1(-0.8 \text { to } 1.1)\end{array}$

0.02

0.03

0.89

0.99

0.34

0.80

Quality of life

\section{EuroQoL EQ-5D-3L \\ EuroQoL EQ-5D visual analogue scale}

KDQOL symptoms

KDQOL burden of disease

KDQOL effect of disease

$-0.04(-0.08$ to 0.00$)$

0.06

$-3(-7$ to 1$)$

-1 ( -3 to 2$)$

0.67

-3 ( -8 to 2$)$

0.20

0.25

KDQOL SF-36 physical component summary

KDQOL SF-36 mental component summary

Renal biochemistry

$\begin{array}{lll}\text { Serum bicarbonate }(\mathrm{mmol} / \mathrm{L}) & 1.1(0.6 \text { to } 1.6) & <0.001 \\ \text { Serum potassium }(\mathrm{mmol} / \mathrm{L}) & 0.0(-0.1 \text { to } 0.1) & 0.80 \\ \text { eGFR }\left(\mathrm{mL} / \mathrm{min} / 1.73 \mathrm{~m}^{2}\right)^{*} & 0.6(-0.8 \text { to } 2.0) & 0.39 \\ \text { Serum creatinine }(\mathrm{umol} / \mathrm{L})^{*} & -8(-28 \text { to } 13) & 0.46 \\ \text { Serum cystatin C }(\mathrm{mg} / \mathrm{L})^{*} & -0.01(-0.17 \text { to } 0.14) & 0.89 \\ \text { Log [urinary albumin/ } & 0.32(-0.05 \text { to } 0.70) & 0.09\end{array}$

creatinine ratio]

Cardiometabolic risk

Log [NT-pro-BNP $(\mathrm{pg} / \mathrm{mL})]$
Total cholesterol (mmol/L)
Systolic blood pressure
$(\mathrm{mmHg})$
Diastolic blood pressure
$(\mathrm{mmHg})$
HbA1c $(\mathrm{mmol} / \mathrm{mol})$

Bone and mineral metabolism

Log [TRACP-5b (IU/L)]

$\log [B s-A L P(\mu g / L)]$

$\log [\mathrm{PTH}(\mathrm{pmol} / \mathrm{L})]$

$\log [25 \mathrm{OHD}(\mathrm{nmol} / \mathrm{L})]$

1,25OHD (pmol/L) (SD)

Serum calcium (mmol/L)
$-2(-5$ to 1$)$

$0.13(-0.18$ to 0.44$)$

0 ( -4 to 3$)$

$$
1(-1 \text { to } 3)
$$$$
1 \text { ( }-1 \text { to } 4)
$$

$$
-0.18(-0.43 \text { to } 0.08)
$$$$
0.01 \text { ( }-0.11 \text { to } 0.13 \text { ) }
$$$$
0.03 \text { ( }-0.14 \text { to } 0.19 \text { ) }
$$$$
3 \text { ( }-3 \text { to } 9)
$$

0.02 (0.00 to 0.04 )$$
-0.08(-0.23 \text { to } 0.06)
$$

Table 2 Secondary outcomes-adjusted treatment effects (repeated measures analyses using data from all available timepoints, adjusted for age, sex and CKD category) (Continued)

\begin{tabular}{lll}
\hline & $\begin{array}{l}\text { Treatment effect (bicarbonate- } \\
\text { placebo) }(95 \% \mathrm{Cl})\end{array}$ & $p$ \\
\hline Serum phosphate (mmol/L) & $0.02(-0.03$ to 0.06$)$ & 0.52 \\
Other & & 0.48 \\
Haemoglobin (g/L) & $-0.1(-0.4$ to 0.2$)$ & 0.67 \\
Albumin (g/L) & $0(-1$ to 1$)$ & 0.39 \\
Log $[T S H(\mathrm{mlU} / \mathrm{L})]$ & $0.07(-0.10$ to 0.24$)$ & \\
\hline
\end{tabular}

*Repeated measures analyses using data from all available timepoints, adjusted for age and sex only

1,25OHD 1,25-dihydroxyvitamin D, 25OHD 25-hydroxyvitamin D, NT-pro-BNP Nterminal pro B-type natriuretic peptide, Bs-ALP bone-specific alkaline phosphatase, eGFR estimated glomerular filtration rate, HbA1c glycosylated haemoglobin, KDQOL kidney disease quality of life, $P T H$ parathyroid hormone,

SF-36 Short-form 36 questionnaire, TRACP-5b tartrate-resistant acid phosphatase $5 \mathrm{~b}, \mathrm{TSH}$ thyroid-stimulating hormone

enrolled the age group most likely to suffer the consequences of CKD; clinically relevant follow-up time; participant, clinician and researcher masking; and broad inclusion criteria. In contrast to almost all previous trials, our use of a placebo control reduced the opportunities for bias. An additional strength was the broad range of outcome measures examined, with a particular focus on physical function and quality of life. These are the outcomes that older people report being most important to them, and this focus is of particular importance in this group of patients with extensive multimorbidity. A narrow focus on a single disease-even in patients with advanced CKDmay not be helpful for holistic decision-making; considering physical function and quality of life enables an assessment of the overall benefit of treatment to patients in a way that organ-specific measures do not.

A number of limitations require further comment. Given the modest increase in serum bicarbonate seen with the dosing schedule used in this trial, it is possible that larger doses of oral bicarbonate are required to increase serum bicarbonate in older people with CKD, although the mechanisms that might underpin such a hypothesis are unclear. Whilst such an approach would be of mechanistic interest, we do not believe that higher doses (more than the six tablets per day) would be well tolerated by older people; the adherence rate would likely be even lower than the moderate adherence rate observed in the current trial. The higher rate of adverse events in the bicarbonate arm, particularly gastrointestinal adverse events, slightly lower physical function measures and lack of a relationship between adherence and treatment effect size, all argue that a higher dose of bicarbonate is unlikely to produce health benefits in this patient group. We cannot exclude a potentially beneficial effect of bicarbonate in different groups of patients with $\mathrm{CKD}$, however. In particular, the current trial enrolled an overwhelmingly white European population. CKD of 
Table 3 Adverse events by MedDRA System Order Class (SOC)

\begin{tabular}{|c|c|c|}
\hline & $\begin{array}{l}\text { Bicarbonate } \\
(n=152)\end{array}$ & $\begin{array}{l}\text { Placebo } \\
(n=148)\end{array}$ \\
\hline \multicolumn{3}{|l|}{$\begin{array}{l}\text { Number of adverse events per } \\
\text { participant (\%) }\end{array}$} \\
\hline 0 & $21(13.8)$ & $16(10.8)$ \\
\hline 1 & $23(15.1)$ & $41(27.7)$ \\
\hline 2 & $27(17.8)$ & $35(23.6)$ \\
\hline 3 & $35(23.0)$ & $15(10.1)$ \\
\hline 4 or more & $46(30.3)$ & $41(27.7)$ \\
\hline Total number of adverse events & 457 & 400 \\
\hline \multicolumn{3}{|l|}{ SOC classification-number of events } \\
\hline $\begin{array}{l}\text { Blood and lymphatic system } \\
\text { disorders }\end{array}$ & 5 & 1 \\
\hline Cardiac disorders & 32 & 19 \\
\hline $\begin{array}{l}\text { Congenital, familial and genetic } \\
\text { disorders }\end{array}$ & 0 & 1 \\
\hline Ear and labyrinth disorders & 1 & 1 \\
\hline Endocrine disorders & 1 & 2 \\
\hline Eye disorders & 6 & 6 \\
\hline Gastrointestinal disorders & 45 & 25 \\
\hline $\begin{array}{l}\text { General disorders and } \\
\text { administration site conditions }\end{array}$ & 14 & 20 \\
\hline Hepatobiliary disorders & 0 & 0 \\
\hline Immune system disorders & 0 & 0 \\
\hline Infections and infestations & 113 & 118 \\
\hline $\begin{array}{l}\text { Injury, poisoning and procedural } \\
\text { complications }\end{array}$ & 41 & 32 \\
\hline Investigations & 5 & 7 \\
\hline $\begin{array}{l}\text { Metabolism and nutrition } \\
\text { disorders }\end{array}$ & 19 & 27 \\
\hline $\begin{array}{l}\text { Musculoskeletal and connective } \\
\text { tissue disorders }\end{array}$ & 28 & 17 \\
\hline $\begin{array}{l}\text { Neoplasms benign, malignant and } \\
\text { unspecified (including cysts } \\
\text { and polyps) }\end{array}$ & 9 & 16 \\
\hline Nervous system disorders & 24 & 12 \\
\hline Psychiatric disorders & 1 & 5 \\
\hline Renal and urinary disorders & 23 & 23 \\
\hline Reproductive system and breast disorders & 4 & 1 \\
\hline $\begin{array}{l}\text { Respiratory, thoracic and } \\
\text { mediastinal disorders }\end{array}$ & 26 & 14 \\
\hline Skin and subcutaneous tissue disorders & 16 & 11 \\
\hline Surgical and medical procedures & 34 & 30 \\
\hline Vascular disorders & 10 & 12 \\
\hline
\end{tabular}

different aetiologies may respond differently and may explain some of the heterogeneity seen in one recent systematic review $[9,27]$.
The original target for recruitment for this trial $(380$ participants) was not reached despite recruiting from 27 UK sites. This was in part due to a lack of clinical equipoise; surveys performed by the trial team during the trial suggested that most UK nephrologists were treating patients with serum bicarbonate concentrations $<22 \mathrm{mmol} /$ $\mathrm{L}$ with bicarbonate already, thus reducing the pool of eligible participants. It is possible that those most likely to respond to bicarbonate supplementation were already taking bicarbonate as part of routine clinical practice, thus further diluting the effect of the intervention. The dropout rate in the trial was considerable and slightly higher than the $10 \%$ per 6 -month follow-up that we anticipated. Such a dropout rate is not unexpected given the high levels of multimorbidity and frailty in this patient population. Although dropout reduces the power of the trial to detect significant treatment effects, this is mitigated to some extent by our use of mixed models with repeated measures for the secondary analyses, which use all available data and effectively impute missing values. Thus, despite the lower than planned sample size, and the lower than anticipated availability of primary outcome data at 12 months, our results exclude the minimum clinically important improvement in the primary outcome with a high degree of confidence. Some investigators have proposed a smaller minimum clinically important difference of 0.5 points for the SPPB [28]; our results also exclude this improvement with a high degree of confidence. Although the trial was designed to have adequate power for the primary outcome and for the EQ-5D outcome, it was not powered to detect clinically important differences in the rate of deterioration of renal function, or for rates of commencing dialysis. We were unable to include the costs of every other medication used in the cost-effectiveness analysis, which could potentially lead to over- or underestimation of costeffectiveness. Given the higher number of adverse events in the bicarbonate group (which would be expected to require additional drugs to treat), it is more likely that additional medication costs would be higher in the bicarbonate arm, further reducing the likelihood that bicarbonate is cost-effective.

\section{Strengths and weaknesses in relation to other studies}

Given the association between metabolic acidosis and a range of adverse outcomes seen in CKD, it would be expected that amelioration of acidosis (i.e. increasing serum bicarbonate) could improve physical function, lessen deterioration in renal function and improve measures of cardiovascular health and bone and mineral metabolism in patients with CKD. A recent systematic review [9] found no randomised controlled trial evidence around the effect of bicarbonate on physical function or quality of life; the current trial therefore provides an important test of the effect of bicarbonate on these important patient-centred 
Table 4 Adjusted (adjusted for baseline differences (age, gender, stage of CKD, baseline EQ-5D health utility score and baseline cost)) mean incremental costs, incremental QALYs/outcomes and incremental cost-effectiveness ratio between sodium bicarbonate vs placebo

\begin{tabular}{|c|c|c|c|}
\hline Analysis & $\begin{array}{l}\text { Incremental mean } \\
\text { costs, } £(95 \% \mathrm{Cl})^{\mathrm{a}, \mathrm{b}, \mathrm{c}}\end{array}$ & $\begin{array}{l}\text { Incremental mean } \\
\text { QALYs/outcomes } \\
(95 \% \text { CI) })^{\text {a, b, c }}\end{array}$ & $\begin{array}{l}\text { Mean incremental } \\
\text { cost-effectiveness ratio } \\
\text { (£/QALY/outcome) } \\
\end{array}$ \\
\hline Complete cases over 12-month follow-up $(n=176)$ & $\begin{array}{l}563.74 \\
\text { (88.18 to } 1154.18)\end{array}$ & $\begin{array}{l}-0.047 \\
(-0.078 \text { to }-0.015)\end{array}$ & Dominated \\
\hline Sensitivity analysis: lower sodium bicarbonate cost ${ }^{d}$ & $\begin{array}{l}352.76 \\
(-154.37 \text { to } 957.45)\end{array}$ & $\begin{array}{l}-0.047 \\
(-0.078 \text { to }-0.015)\end{array}$ & Dominated \\
\hline Sensitivity analysis: lower inpatient stay cost ${ }^{\mathrm{e}}$ & $\begin{array}{l}539.03 \\
(109.13 \text { to } 1050.45)\end{array}$ & $\begin{array}{l}-0.046 \\
(-0.078 \text { to }-0.015)\end{array}$ & Dominated \\
\hline Sensitivity analysis: using ICECAP value ${ }^{f}$ & $\begin{array}{l}636.20 \\
(187.59 \text { to } 1189.24)\end{array}$ & $\begin{array}{l}-0.017 \\
(-0.032 \text { to } 0.0001)\end{array}$ & Dominated \\
\hline Sensitivity analysis: using life satisfaction value ${ }^{g}$ & $\begin{array}{l}580.19 \\
(143.38 \text { to } 1130.11)\end{array}$ & $\begin{array}{l}-0.396 \\
(-0.733 \text { to }-0.059)\end{array}$ & Dominated \\
\hline Complete cases over 24-month follow-up $(n=114)^{h}$ & $\begin{array}{l}591.00 \\
(166.29 \text { to } 1078.36)\end{array}$ & $\begin{array}{l}-0.083 \\
(-0.166 \text { to }-0.005)\end{array}$ & Dominated \\
\hline Sensitivity analysis: lower sodium bicarbonate cost $^{d}$ & $\begin{array}{l}242.59 \\
(-179.63 \text { to } 720.27)\end{array}$ & $\begin{array}{l}-0.083 \\
(-0.166 \text { to }-0.005)\end{array}$ & Dominated \\
\hline Sensitivity analysis: lower inpatient stay cost ${ }^{\mathrm{e}}$ & $\begin{array}{l}593.74 \\
(191.37 \text { to } 1072.07)\end{array}$ & $\begin{array}{l}-0.083 \\
(-0.166 \text { to }-0.005)\end{array}$ & Dominated \\
\hline Sensitivity analysis: using ICECAP value ${ }^{f}$ & $\begin{array}{l}598.87 \\
(215.69 \text { to } 1052.43)\end{array}$ & $\begin{array}{l}-0.051 \\
(-0.095 \text { to }-0.010)\end{array}$ & Dominated \\
\hline Sensitivity analysis: using life satisfaction value ${ }^{g}$ & $\begin{array}{l}682.44 \\
(257.28 \text { to } 1142.63)\end{array}$ & $\begin{array}{l}-0.974 \\
(-1.762 \text { to }-0.190)\end{array}$ & Dominated \\
\hline $\begin{array}{l}\text { Complete cases over } 24 \text {-month follow-up and all participants starting } \\
\text { renal replacement therapy during the trial }(n=161)^{\mathrm{h}}\end{array}$ & $\begin{array}{l}808.93 \\
(-4124.71 \text { to } 5411.89)\end{array}$ & $\begin{array}{l}-0.074 \\
(-0.151 \text { to }-0.003)\end{array}$ & Dominated \\
\hline Sensitivity analysis: lower sodium bicarbonate cost ${ }^{d}$ & $\begin{array}{l}534.61 \\
(-4385.90 \text { to } 5149.69)\end{array}$ & $\begin{array}{l}-0.074 \\
(-0.150 \text { to }-0.003)\end{array}$ & Dominated \\
\hline Sensitivity analysis: lower inpatient stay cost ${ }^{\mathrm{e}}$ & $\begin{array}{l}817.21 \\
(-4097.90 \text { to } 5415.22)\end{array}$ & $\begin{array}{l}-0.073 \\
(-0.151 \text { to }-0.001)\end{array}$ & Dominated \\
\hline Sensitivity analysis: using ICECAP value $\mathrm{f}^{\mathrm{f}, \mathrm{i}}$ & $\begin{array}{l}422.08 \\
(-4091.74 \text { to } 4629.60)\end{array}$ & $\begin{array}{l}-0.046 \\
(-0.090 \text { to }-0.002)\end{array}$ & Dominated \\
\hline Sensitivity analysis: lower dialysis cost ${ }^{j}$ & $\begin{array}{l}600.26 \\
(-3560.78 \text { to } 4379.06)\end{array}$ & $\begin{array}{l}-0.075 \\
(-0.154 \text { to }-0.001)\end{array}$ & Dominated \\
\hline Sensitivity analysis: higher dialysis cost ${ }^{k}$ & $\begin{array}{l}899.41 \\
(-4327.11 \text { to } 5714.04)\end{array}$ & $\begin{array}{l}-0.074 \\
(-0.156 \text { to } 0.002)\end{array}$ & Dominated \\
\hline Sensitivity analysis: using life satisfaction value ${ }^{g, 1}$ & $\begin{array}{l}928.18 \\
(-4373.23 \text { to } 5729.68)\end{array}$ & $\begin{array}{l}-0.072 \\
(-1.366 \text { to } 0.002)\end{array}$ & Dominated \\
\hline
\end{tabular}

\footnotetext{
${ }^{\mathrm{a}}$ Bootstrapped non-parametric $95 \%$ confidence interval (2.5th/97.5th percentile)
}

${ }^{\mathrm{b}}$ Generalised linear model with $\gamma$ distribution and power 0.65 link function to estimate incremental costs and ordinary least squares regression to estimate incremental QALYs (complete cases)

${ }^{\mathrm{C}}$ Generalised linear model with Gaussian distribution and power 0.5 link function to estimate incremental costs and ordinary least squares regression to estimate incremental QALYs (114 complete cases +47 participants starting renal replacement therapy during the trial with baseline EQ-5D). For incomplete cases, missing cost data were assumed to be zero and missing EQ-5D data were imputed by carrying forward the last observation

${ }^{\mathrm{d}}$ Applied average cost of three generic sodium bicarbonate $500 \mathrm{mg}$ with the lowest price, £0.14/day

eApplied average of lower quartile unit cost for non-elective inpatient and elective inpatient bed days, $£ 287 /$ day

${ }^{f}$ Adjusted for baseline differences (age, gender, stage of CKD, baseline ICECAP value and baseline cost)

${ }^{9}$ Adjusted for baseline differences (age, gender, stage of CKD, baseline life satisfaction value and baseline cost)

hiscounted at 3.5\% per year

'Two participants from the bicarbonate group without any ICECAP data were excluded from the analysis, $n=159$

${ }^{\mathrm{j} A p p l i e d}$ average of lower quartile unit cost for haemodialysis ( $\left.£ 134 / \mathrm{visit}\right)$ and peritoneal dialysis ( $\left.£ 66 / \mathrm{visit}\right)$

${ }^{k}$ Applied average of upper quartile unit cost for haemodialysis ( $\left.£ 180 / v i s i t\right)$ and peritoneal dialysis ( $£ 77 /$ visit)

'Two participants (1 from each group) without any life satisfaction data were excluded from the analysis, $n=159$

Abbreviations: QALYs quality-adjusted life years, ICER incremental cost-effectiveness ratio, SA sensitivity analysis, ICECAP Investigating Choice Experiments for the preferences of older people CAPability tool, CKD chronic kidney disease 


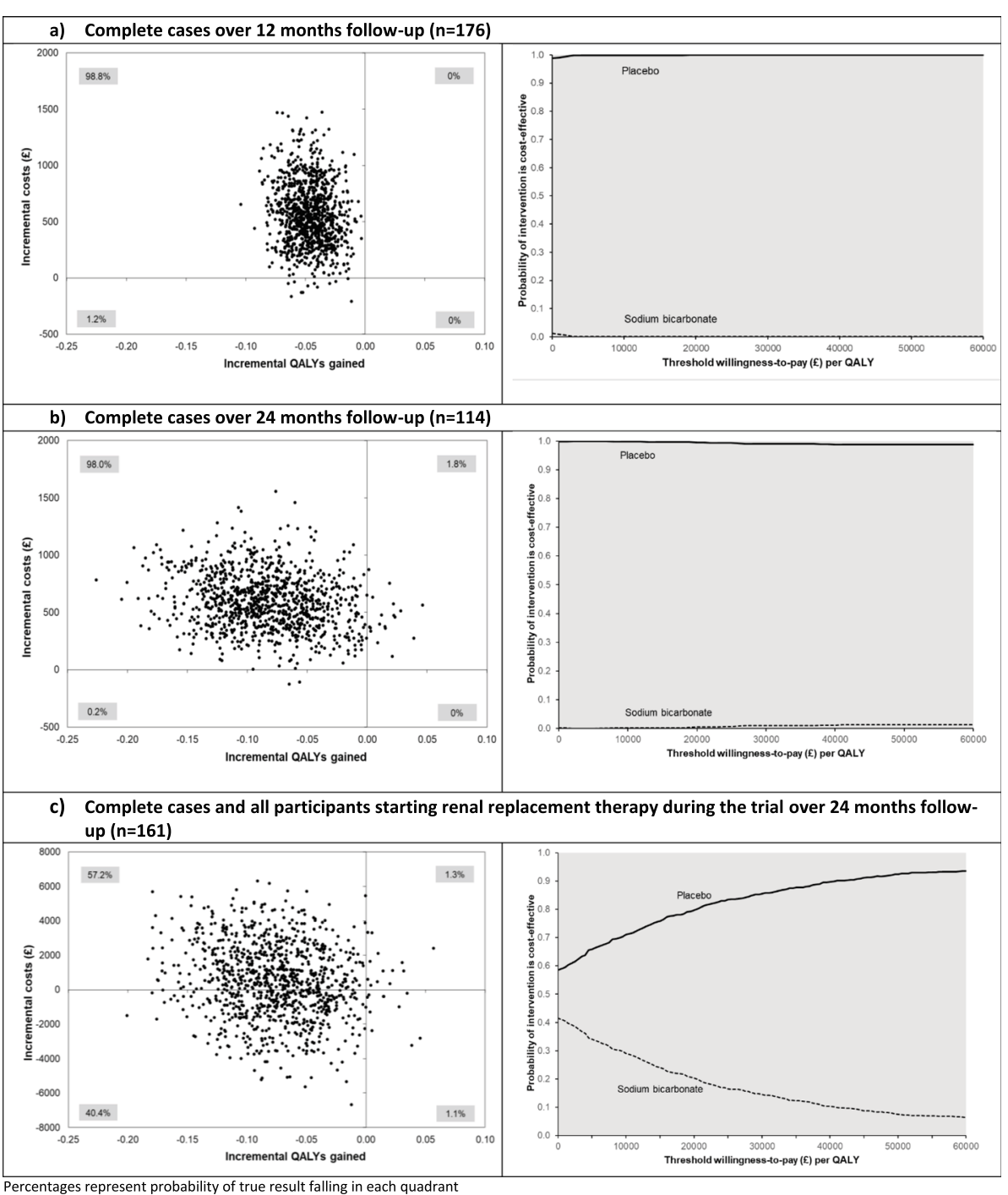

Fig. 4 Scatterplot and cost-effectiveness acceptability curve of incremental cost difference and incremental QALY difference between randomised groups

outcomes. A previous single-centre trial of bicarbonate versus usual care found progressive increases in serum bicarbonate over a 2-year period in the bicarbonate group; measures of anthropometry were better in the bicarbonate group, and fewer participants progressed to end-stage renal disease in the bicarbonate group (4/67 vs 22/67) [27]. However, this trial did not use placebo, and thus, healthcare providers and participants were aware of group allocation. It is possible that the lack of masking could inflate the effect size seen in this trial, perhaps by an impact on decision-making around renal replacement and on other treatment decisions driven by knowledge of whether a participant was receiving bicarbonate. Participants in this previous trial were recruited from a single centre and were much younger (mean age 55 years), and a high percentage were of south Asian or black origin.
In our trial, oral bicarbonate produced only a modest increase in serum bicarbonate concentration relative to placebo; this difference was maximal at 3 months and converged with the placebo group by 24 months. Bicarbonate concentrations in the placebo group rose gradually over time, which again limited the contrast between the two groups; this may be due in part to the pragmatic nature of the trial design, where physicians were free to switch participants to bicarbonate therapy if this was felt to be clinically indicated. The effect seen in both recent systematic reviews $[9,10]$ was greater than that observed in the current trial, with a mean $3 \mathrm{mmol} / \mathrm{L}$ higher serum bicarbonate in the treatment arm compared to control by the end of follow-up; restricting analyses to 1-year followup gave similar results. It is likely that the combination of a modest dose of bicarbonate (in comparison to some 
other trials) and suboptimal adherence contributed to this finding, but as this dosing regimen reflects current UK practice, patients in the real world are likely to sustain similarly modest increases in serum bicarbonate concentrations. A recent dose-ranging pilot trial (the BASE trial) suggested that higher dose (approximately $5 \mathrm{~g} /$ day) of bicarbonate was more effective than lower dose (approximately $3 \mathrm{~g} /$ day) of bicarbonate in increasing serum bicarbonate concentrations in patients with CKD 3 or 4; the higher dose provided an additional $1.3-\mathrm{mmol} / \mathrm{L}$ increase in mean serum bicarbonate concentration compared to the lower dose [29]. Most trials included in the systematic review used a 'treat-to-target' approach. This would allow participants with lower bicarbonate concentrations to receive higher doses but could also potentially increase adverse events. Although previous small trials have used such an approach successfully without evidence of significant harm [30], harms have not been well reported in bicarbonate trials to date, and our more comprehensive approach to adverse event reporting revealed an excess of events in the bicarbonate arm. Our ability to titrate doses to the levels used in some previous trials was limited; we made the decision at the design stage to limit titration to doubling of the dose at 3 months, which was performed only if serum bicarbonate concentrations were still $<22 \mathrm{mmol} / \mathrm{L}$. Although this decision was taken to reflect the state of usual UK bicarbonate prescribing practice, practice is heterogeneous and higher doses of bicarbonate may have greater effects for some patients. In addition, for participants in the treatment group with only modest degrees of acidosis, only a small improvement in serum bicarbonate was required to cross this threshold, which limited the number of participants for whom a higher dose of bicarbonate was prescribed.

Although no studies have studied the association between serum bicarbonate levels and our primary outcome of the Short Physical Performance Battery, observational data suggest a $7-8 \%$ increase in incident functional limitation for each $1 \mathrm{mmol} / \mathrm{L}$ lower bicarbonate level in a cohort of older people, although few of this cohort had CKD [7]. Similarly, participants in NHANES with a serum bicarbonate concentration $<23 \mathrm{mmol} / \mathrm{L}$ had a $14 \%$ higher risk of low gait speed for every $1 \mathrm{mmol} / \mathrm{L}$ lower bicarbonate concentration [6]. These results are not incompatible with our trial results; larger increases in serum bicarbonate concentration may be required to produce clinically meaningful changes in physical performance measures or biochemical parameters such as bone metabolism markers.

Most trials in the systematic review did not use placebo. The unmasked nature of these trials is likely to have contributed to the larger treatment effects observed and may also have influenced decision-making about the commencement of renal replacement therapy in some trials. Differential dropout is unlikely to explain the small difference we observed in the current trial as dropout numbers at each timepoint were similar in each arm. Although adherence was not optimal in the current trial, the dose of bicarbonate prescribed was similar to that used in a previous trial [25] that observed greater increases in serum bicarbonate, and both the dose used and the adherence levels observed in our trial are likely to reflect those seen in clinical practice, especially amongst older people taking a large number of medications. A modest difference in eGFR at both 1 year and at the end of follow-up was seen in the recent systematic review, although too few data were available to calculate the mean rate of decline in eGFR. No significant treatment effect on blood pressure or body weight was seen in the systematic review, and our findings are consistent with these observations.

A number of other trials of bicarbonate therapy are currently in progress or have just been published [31-33]. These trials target a range of severities of CKD (categories $3 \mathrm{~b}$ to 5 ), a range of entry serum bicarbonate concentrations and for two of the trials, a strategy of dose adjustment to keep serum bicarbonate $>24 \mathrm{mmol} / \mathrm{L}$ is employed. None of these trials targets older people as a specific group however. The large UBI trial, based in Italy, randomised 795 individuals with CKD stage $3 \mathrm{~b}$ or 4 to usual care or a strategy of bicarbonate treatment to a target of $24-28 \mathrm{mmol} / \mathrm{L}$. The mean dose required to reach this serum bicarbonate concentration (some $3-4 \mathrm{mmol} / \mathrm{L}$ higher than in the usual care arm) was $6 \mathrm{~g} /$ day of sodium bicarbonate-much higher than used in the BiCARB trial. The UBI trial showed a significant reduction in the rate of progression of CKD, death and dialysis commencement in the bicarbonate arm compared to usual care [34]. Patients in this trial were slightly younger (mean age 67 years) and had considerably better renal function (mean eGFR of 36 $\mathrm{mL} / \mathrm{min} / 1.73 \mathrm{~m}^{2}$ ), but the trial was not placebo-controlled or blinded. In contrast, a smaller $(n=149)$ placebocontrolled randomised trial in patients with CKD stages 3 and 4 with similar baseline eGFR found a 1-2-mmol/L increase in serum bicarbonate concentration in the treatment arm compared to placebo, using a dose equivalent to between 2 and $2.5 \mathrm{~g}$ per day of sodium bicarbonate [32]. Similar to the findings of the BiCARB trial, there was no effect of bicarbonate supplementation on eGFR, muscle function, blood pressure or quality of life.

Recent trial data suggests that the new hydrochloric acid binder veverimer can successfully increase serum bicarbonate concentrations; a mean $3-\mathrm{mmol} / \mathrm{L}$ increase compared to placebo was observed over 12 weeks [35]. In addition, veverimer improved diseasespecific quality of life measured using the KDQoL tool, and improved chair stand time relative to placebo over 1 year of treatment [36], albeit in a younger population (mean age 61 years) than studied in the current trial. 


\section{Conclusions}

\section{Implications and future research}

Our results suggest that at least for patients aged 60 and over with CKD GFR categories 4 and $5,1.5$ to $3 \mathrm{~g}$ per day of oral bicarbonate does not produce any health benefits and may be associated with net harms. Whilst other indications for control of acidosis exist (for example high potassium concentrations), evidence from the current trial suggests that the additional cost, treatment burden and side effects of oral bicarbonate may not justify its use in older people with advanced CKD and mild degrees of metabolic acidosis (i.e. serum bicarbonate concentration $<22 \mathrm{mmol} /$ L). Raising bicarbonate levels by an amount sufficient to produce useful clinical effects will require larger doses than we used in this trial and is likely to require a 'treat-to-target' strategy. However, such doses may not be tolerated by many older people. Alternative strategies, such as the use of hydrochloric acid binders, may provide a way round this issue, but such agents need to be tested against current practice in representative groups of patients, using a range of outcomes relevant to older people including physical function, quality of life and deterioration of renal function.

\section{Supplementary information}

Supplementary information accompanies this paper at https://doi.org/10. 1186/s12916-020-01542-9.

Additional file 1. Comparison of baseline characteristics of participants completing and not completing SPPB (primary outcome) at 12 months.

\section{Abbreviations \\ Cl: Confidence interval; CKD: Chronic kidney disease; DMC: Data Monitoring Committee; eGFR: Estimated glomerular filtration rate; EQ-5D: EuroQoL 5 dimension tool; ICECAP-O: ICEpop CAPability measure for Older people; KDQoL: Kidney Disease Quality of Life; MDRD4: Modified Diet in Renal Disease 4 variable equation; NHANES: National Health and Nutrition Examination Survey; NHS: National Health Service; NIHR: National Institute for Health Research; QALY: Quality-adjusted life years; SPPB: Short Physical Performance Battery; TSC: Trial Steering Committee}

\section{Acknowledgements}

We acknowledge the support received via the NHS Scotland Support for Science scheme; the NIHR Renal and Ageing Comprehensive Research Networks; and the work of all of the research nurses, local investigators and study teams at sites; Tayside Clinical Trials Unit staff; and most importantly all those with kidney disease who participated in the trial. Professor Witham acknowledges support from the NIHR Newcastle Biomedical Research Centre. In addition, we acknowledge the support and advice we received from the independent Trial Steering Committee members (Professor David Stott, Professor Patrick Mark, Professor Tahir Masud and Mr. Alex Stephen) and the independent Data Monitoring Committee (Professor Alex McConnachie, Professor David Wheeler, Dr. Nicosha de Souza, Professor Andrew Clegg). We also acknowledge the efforts of all the investigators, site research nurses and support teams.

*Study group author list

\begin{tabular}{lll}
\hline Author & \multicolumn{1}{c}{ Affiliation } & \multicolumn{1}{c}{ Email } \\
Miles D Witham & AGE Research Group, NIHR Newcastle & Miles.Witham \\
& Biomedical Research Centre, & @newcastle.ac.uk \\
& Newcastle University and Newcastle- &
\end{tabular}

(Continued)

\begin{tabular}{|c|c|c|}
\hline & $\begin{array}{l}\text { upon-Tyne Hospitals Trust; School of } \\
\text { Medicine, University of Dundee }\end{array}$ & \\
\hline Margaret Band & $\begin{array}{l}\text { Tayside Clinical Trials Unit, University } \\
\text { of Dundee }\end{array}$ & $\begin{array}{l}\text { m.band } \\
\text { @dundee.ac.uk }\end{array}$ \\
\hline Aimun Ahmed & $\begin{array}{l}\text { Lancashire Teaching Hospitals NHS } \\
\text { Foundation Trust }\end{array}$ & $\begin{array}{l}\text { Aimun.Ahmed } \\
\text { @lthtr.nhs.uk }\end{array}$ \\
\hline $\begin{array}{l}\text { Michael K } \\
\text { Almond }\end{array}$ & $\begin{array}{l}\text { Southend University Hospital NHS } \\
\text { Trust }\end{array}$ & $\begin{array}{l}\text { Mike.almond1 } \\
\text { @gmail.com }\end{array}$ \\
\hline $\begin{array}{l}\text { Gowrie } \\
\text { Balasubramaniam }\end{array}$ & $\begin{array}{l}\text { Southend University Hospital NHS } \\
\text { Trust }\end{array}$ & $\begin{array}{l}\text { g. } \\
\text { balasubramaniam } \\
\text { @southend.nhs. } \\
\text { uk }\end{array}$ \\
\hline $\begin{array}{l}\text { Kolitha } \\
\text { Basnayake }\end{array}$ & $\begin{array}{l}\text { Brighton and Sussex University } \\
\text { Hospitals NHS Trust }\end{array}$ & $\begin{array}{l}\text { k.basnayake } \\
\text { @nhs.net }\end{array}$ \\
\hline $\begin{array}{l}\text { Deepak } \\
\text { Bhatnagar }\end{array}$ & The Royal Oldham Hospital & $\begin{array}{l}\text { Deepak. } \\
\text { Bhatnagar } \\
\text { @manchester.ac. } \\
\text { uk }\end{array}$ \\
\hline Anthony Chan & Mid Essex Hospital Services NHS Trust & $\begin{array}{l}\text { Anthony.Chan } \\
@ \text { @meht.nhs.uk }\end{array}$ \\
\hline Huey Yi Chong & $\begin{array}{l}\text { Health Economics Research Unit, } \\
\text { University of Aberdeen }\end{array}$ & $\begin{array}{l}\text { huey.chong } \\
\text { @abdn.ac.uk }\end{array}$ \\
\hline Peter T Donnan & $\begin{array}{l}\text { Division of Population Health and } \\
\text { Genomics, Medical School, University } \\
\text { of Dundee }\end{array}$ & $\begin{array}{l}\text { p.t.donnan } \\
\text { @dundee.ac.uk }\end{array}$ \\
\hline Neill Duncan & $\begin{array}{l}\text { Imperial College Renal and Transplant } \\
\text { Centre, Hammersmith Hospital }\end{array}$ & $\begin{array}{l}\text { Neill.Duncan } \\
\text { @nhs.net }\end{array}$ \\
\hline Geeta Hampson & $\begin{array}{l}\text { Department of Clinical Chemistry and } \\
\text { Metabolic Medicine, Guys and St } \\
\text { Thomas's NHS Trust }\end{array}$ & $\begin{array}{l}\text { geeta.hampson } \\
\text { @kcl.ac.uk }\end{array}$ \\
\hline May Khei Hu & NHS Grampian & $\begin{array}{l}\text { Maykhei.hu@nhs. } \\
\text { net }\end{array}$ \\
\hline Philip A Kalra & Salford Royal NHS Foundation Trust & $\begin{array}{l}\text { philip.kalra } \\
\text { @srft.nhs.uk }\end{array}$ \\
\hline Gwen Kennedy & $\begin{array}{l}\text { The Immunoassay Biomarker Core } \\
\text { Laboratory, University of Dundee }\end{array}$ & $\begin{array}{l}\text { g.y.kennedy } \\
\text { @dundee.ac.uk }\end{array}$ \\
\hline Adam Kirk & Portsmouth Hospitals NHS Trust & $\begin{array}{l}\text { apothad@gmail. } \\
\text { com }\end{array}$ \\
\hline Edmund J Lamb & $\begin{array}{l}\text { East Kent Hospitals University NHS } \\
\text { Foundation Trust }\end{array}$ & elamb@nhs.net \\
\hline Stewart Lambie & NHS Highland & $\begin{array}{l}\text { stewart.lambie2 } \\
\text { @nhs.net }\end{array}$ \\
\hline Roberta Littleford & University of Queensland & $\begin{array}{l}\text { r.littleford } \\
\text { @uq.edu.au }\end{array}$ \\
\hline Paul McNamee & $\begin{array}{l}\text { Health Economics Research Unit, } \\
\text { University of Aberdeen }\end{array}$ & $\begin{array}{l}\text { p.mcnamee } \\
\text { @abdn.ac.uk }\end{array}$ \\
\hline Biswa Mishra & The Royal Oldham Hospital & $\begin{array}{l}\text { Biswa.mishra } \\
\text { @pat.nhs.uk }\end{array}$ \\
\hline Sandip Mitra & $\begin{array}{l}\text { Manchester University Hospitals NHS } \\
\text { Foundation Trust }\end{array}$ & $\begin{array}{l}\text { Sandip.Mitra } \\
\text { @cmft.nhs.uk }\end{array}$ \\
\hline Johann Nicholas & $\begin{array}{l}\text { Shrewsbury and Telford Hospital NHS } \\
\text { Trust }\end{array}$ & $\begin{array}{l}\text { johann.nicholas } \\
\text { @nhs.net }\end{array}$ \\
\hline Deirdre Plews & $\begin{array}{l}\text { Tayside Clinical Trials Unit, University } \\
\text { of Dundee }\end{array}$ & $\begin{array}{l}\text { Deirdre.plews } \\
\text { @outlook.com }\end{array}$ \\
\hline Petra Rauchhaus & $\begin{array}{l}\text { Tayside Clinical Trials Unit, University } \\
\text { of Dundee }\end{array}$ & $\begin{array}{l}\text { P.Rauchhaus } \\
\text { @dundee.ac.uk }\end{array}$ \\
\hline
\end{tabular}


(Continued)

\begin{tabular}{|c|c|c|}
\hline Roy L Soiza & $\begin{array}{l}\text { Ageing Clinical and Experimental } \\
\text { Research, University of Aberdeen }\end{array}$ & $\begin{array}{l}\text { r.l.soiza } \\
\text { @abdn.ac.uk }\end{array}$ \\
\hline Paul E Stevens & $\begin{array}{l}\text { East Kent Hospitals University NHS } \\
\text { Foundation Trust }\end{array}$ & $\begin{array}{l}\text { pstevens } \\
@ \text { @hs.net }\end{array}$ \\
\hline $\begin{array}{l}\text { Deepa } \\
\text { Sumukadas }\end{array}$ & $\begin{array}{l}\text { Department of Medicine for the } \\
\text { Elderly, NHS Tayside }\end{array}$ & $\begin{array}{l}\text { d.sumukadas } \\
\text { @nhs.net }\end{array}$ \\
\hline Wai Tse & $\begin{array}{l}\text { University Hospitals Plymouth NHS } \\
\text { Trust }\end{array}$ & $\begin{array}{l}\text { wai-yee.tse } \\
\text { @nhs.net }\end{array}$ \\
\hline Graham Warwick & $\begin{array}{l}\text { John Walls Renal Unit, University } \\
\text { Hospitals of Leicester }\end{array}$ & $\begin{array}{l}\text { Graham.warwick } \\
\text { @uhl-tr.nhs.uk }\end{array}$ \\
\hline Martin Wilkie & $\begin{array}{l}\text { Sheffield Teaching Hospital NHS } \\
\text { Foundation Trust }\end{array}$ & $\begin{array}{l}\text { martin.wilkie } \\
\text { @sth.nhs.uk }\end{array}$ \\
\hline Georgia Winnett & $\begin{array}{l}\text { Basildon and Thurrock University } \\
\text { Hospitals NHS Foundation Trust }\end{array}$ & $\begin{array}{l}\text { Georgia.Winnett } \\
\text { @btuh.nhs.uk }\end{array}$ \\
\hline Alison Avenell & $\begin{array}{l}\text { Health Services Research Unit, } \\
\text { University of Aberdeen }\end{array}$ & $\begin{array}{l}\text { a.avenell } \\
\text { @abdn.ac.uk }\end{array}$ \\
\hline
\end{tabular}

\section{Authors' contributions}

MDW designed and led the trial, led the interpretation and wrote the paper. MB designed the trial, contributed to the interpretation and critically revised the text. AA collected the data and critically revised the text. MKA collected the data and critically revised the text. GB collected the data and critically revised the text. KB collected the data and critically revised the text. DB collected the data and critically revised the text. AC collected the data and critically revised the text. HYC led the health economic analysis, contributed to the interpretation and critically revised the text. PTD contributed to the main trial data analysis and interpretation and critically revised the text. ND collected the data and critically revised the text. GH designed the trial, co-led the sample analysis, contributed to the interpretation and critically revised the text. MKH led the systematic review, analysed the systematic review data, contributed to the interpretation and critically revised the text. PAK collected the data, contributed to the interpretation and critically revised the text. GK co-led the sample analysis, contributed to the interpretation and critically revised the text. AK collected the data and critically revised the text. EJL designed the trial, co-led the sample analysis, contributed to the interpretation and critically revised the text. SL collected the data and critically revised the text. RL designed the trial, contributed to the interpretation and critically revised the text. PM designed the trial (health economic component) and health economic analysis, contributed to the interpretation and critically revised the text. BM collected the data and critically revised the text. SM collected data and critically revised the text. JN collected the data and critically revised the text. DP designed the trial, contributed to the interpretation and critically revised the text. PR contributed to the main trial data analysis, contributed to the interpretation and critically revised the text. RLS designed the trial, led the systematic review, contributed to the interpretation and critically revised the text. PES collected the data and critically revised the text. DS designed the trial, contributed to the interpretation and critically revised the text. WT collected the data and critically revised the text. GW collected the data, contributed to the interpretation and critically revised the text. MW collected the data and critically revised text. GW collected the data and critically revised the text. AA designed the trial, contributed to the interpretation and critically revised the text. The authors read and approved the final manuscript.

\section{Funding}

The BiCARB trial was funded by the National Institute for Health Research Health Technology Assessment programme (project reference 10/71/01). The views expressed are those of the authors and not necessarily those of the $\mathrm{NIHR}$ or the Department of Health and Social Care.

The funder of the study had input into the study design via the original commissioning call specification. The funder had no other role in the study design, data collection, data analysis, data interpretation, or writing of the report. The corresponding author had full access to all the data in the study and had final responsibility for the decision to submit.

Disclaimer: The Health Services Research Unit and Health Economics Research Unit are core funded by the Chief Scientist Office of the Scottish Government Health and Social Care Directorate.

\section{Availability of data and materials}

Deidentified, individual participant-level data are available to bona-fide academic research teams, subject to submission of an outline of the purpose for which it will be used, and subject to approval by an independent Data Access Committee process hosted by the trial Sponsor (University of Dundee). Please contact the corresponding author or the Sponsor (TASCgovernance@dundee.ac.uk).

\section{Ethics approval and consent to participate}

Ethical approval was granted by the East of Scotland NHS Research Ethics Committee (approval 12/ES/0023); the trial was also approved by the UK Medicines and Healthcare Regulatory Authority (EudraCT number 2011005271-16; Clinical Trial Authorisation number 41692/0001/001-0001). All participants provided written informed consent prior to participation.

\section{Consent for publication}

Not applicable

\section{Competing interests}

All authors have completed the ICMJE uniform disclosure form at www. icmje.org/coi_disclosure.pdf and declare no support for the work beyond funding of the trial by the NIHR HTA programme and infrastructure support detailed in the "Acknowledgements" section. Professor Donnan is a member of the New Drugs Committee of the Scottish Medicines Consortium and has received recent grants from Gilead Sciences and Shire Pharmaceuticals. Dr. Basnayake currently works for Fresenius Medical Care UK. Dr. Kirk currently works as a clinical director for MyMHealth. The other authors declare that they have no competing interests.

Received: 18 October 2019 Accepted: 25 February 2020

Published online: 09 April 2020

\section{References}

1. Coresh J, Selvin E, Stevens LA, Manzi J, Kusek JW, Eggers P, et al. Prevalence of chronic kidney disease in the United States. JAMA. 2007;298:2038-47.

2. Eustace JA, Astor B, Muntner PM, Ikizler TA, Coresh J. Prevalence of acidosis and inflammation and their association with low serum albumin in chronic kidney disease. Kidney Int. 2004;65:1031-40.

3. Menon V, Tighiouart H, Vaughn NS, Beck GJ, Kusek JW, Collins AJ, et al. Serum bicarbonate and long-term outcomes in CKD. Am J Kidney Dis. 2010; 56:907-14.

4. Goldenstein L, Driver TH, Fried LF, Rifkin DE, Patel KV, Yenchek RH, et al. Serum bicarbonate concentrations and kidney disease progression in community-living elders: the Health, Aging, and Body Composition (Health ABC) Study. Am J Kidney Dis. 2014;64:542-9.

5. Dobre M, Yang W, Chen J, Drawz P, Hamm LL, Horwitz E, et al. Association of serum bicarbonate with risk of renal and cardiovascular outcomes in CKD: a report from the Chronic Renal Insufficiency Cohort (CRIC) study. Am J Kidney Dis. 2013;62:670-8.

6. Abramowitz MK, Hostetter TH, Melamed ML. Association of serum bicarbonate levels with gait speed and quadriceps strength in older adults. Am J Kidney Dis. 2011;58:29-38.

7. Yenchek R, Ix JH, Rifkin DE, Shlipak MG, Sarnak MJ, Garcia M, et al. Association of serum bicarbonate with incident functional limitation in older adults. Clin J Am Soc Nephrol. 2014;9:2111-6.

8. Chen W, Melamed ML, Abramowitz MK. Serum bicarbonate and bone mineral density in US adults. Am J Kidney Dis. 2015;65:240-8.

9. Hu MK, Soiza RL, Witham MD. Oral bicarbonate therapy in chronic kidney disease: a systematic review and meta-analysis of randomised controlled trial. J Clin Med. 2019;8:E208.

10. Navaneethan SD, Shao J, Buysse J, Bushinsky DA. Effects of treatment of metabolic acidosis in CKD: a systematic review and meta-analysis. Clin J Am Soc Nephrol. 2019;14(7):1011-20. 
11. Kidney Disease: Improving Global Outcomes (KDIGO). 2012. CKD evaluation and management guideline. URL: https://kdigo.org/guidelines/ckdevaluation-and-management/. Accessed 6 Jan 2019.

12. National Institute for Health and Care Excellence. Clinical Guideline CG182: chronic kidney disease in adults: assessment and management. 2015. URL: https://www.nice.org.uk/guidance/cg182. Accessed 6 Jan 2019.

13. Roberts $H$, Khee TS, Philp I. Setting priorities for measures of performance for geriatric medical services. Age Ageing. 1994;23(2):154-7.

14. Witham MD, Band MM, Littleford RC, Avenell A, Soiza RL, McMurdo ME, Sumukadas D, Ogston SA, Lamb EJ, Hampson G, McNamee P, BiCARB Study Group. Does oral sodium bicarbonate therapy improve function and quality of life in older patients with chronic kidney disease and low-grade acidosis (the BiCARB trial)? Study protocol for a randomized controlled trial. Trials. 2015;16:326

15. Levey AS, Coresh J, Greene T, Stevens LA, Zhang YL, Hendriksen S, Kusek JW, Van Lente F, Chronic Kidney Disease Epidemiology Collaboration. Using standardized serum creatinine values in the modification of diet in renal disease study equation for estimating glomerular filtration rate. Ann Intern Med. 2006:145:247-54

16. Guralnik JM, Simonsick EM, Ferrucci L, Glynn RJ, Berkman LF, Blazer DG, et al. A short physical performance battery assessing lower extremity function: association with self-reported disability and prediction of mortality and nursing home admission. J Gerontol. 1994;49:M85-94.

17. Guralnik JM, Ferrucci L, Simonsick EM, Salive ME, Wallace RB. Lowerextremity function in persons over the age of 70 years as a predictor of subsequent disability. N Engl J Med. 1995;332:556-61.

18. Wennie Huang WN, Perera S, Vanswearingen J, Studenski S. Performance measures predict onset of activity of daily living difficulty in communitydwelling older adults. J Am Geriatr Soc. 2010;58:844-52.

19. EuroQol Group. EuroQol--a new facility for the measurement of healthrelated quality of life. Health Policy. 1990;16:199-208.

20. Hays RD, Kallich JD, Mapes DL, Coons SJ, Carter WB. Development of the kidney disease quality of life (KDQOL) instrument. Qual Life Res. 1994;3:329-38.

21. McMurdo ME, Sugden J, Argo I, Boyle P, Johnston DW, Sniehotta FF, et al. Do pedometers increase physical activity in sedentary older women? A randomized controlled trial. J Am Geriatr Soc. 2010:58:2099-106.

22. Walters SJ, Brazier JE. Comparison of the minimally important difference for two health state utility measures: EQ-5D and SF-6D. Qual Life Res. 2005;14: 1523-32.

23. Sumukadas D, Witham MD, Struthers AD, McMurdo MET. Effect of perindopril on physical function in elderly people with functional impairment: a randomised controlled trial. CMAJ. 2007;177:867-74

24. Burton LA, Sumukadas D, Witham MD, Struthers AD, McMurdo ME. Effect of spironolactone on physical performance in older people with self-reported physical disability. Am J Med. 2013;126:590-7.

25. NHS Reference Costs 2016-17. Department of Health. 2017. URL: https:// improvement.nhs.uk/resources/reference-costs/. Accessed 19 Jan 2019.

26. Curtis L, Burns A. Unit costs of health and social care 2017. Canterbury: Personal Social Services Research Unit, University of Kent; 2017.

27. Brito-Ashurst I, Varagunam M, Raftery MJ, Yaqoob MM. Bicarbonate supplementation slows progression of CKD and improves nutritional status. J Am Soc Nephrol. 2009;20:2075-84.

28. Perera S, Mody SH, Woodman RC, Studenski SA. Meaningful change and responsiveness in common physical performance measures in older adults. J Am Geriatr Soc. 2006:53:743-9.

29. Raphael KL, Isakova T, Ix JH, Raj DS, Wolf M, Fried LF, et al. A randomized trial comparing the safety, adherence, and pharmacodynamics profiles of two doses of sodium bicarbonate in CKD: the BASE pilot trial. J Am Soc Nephrol. 2020;31:161-74.

30. Phisitkul S, Khanna A, Simoni J, Broglio K, Sheather S, Rajab MH, Wesson DE. Amelioration of metabolic acidosis in patients with low GFR reduced kidney endothelin production and kidney injury, and better preserved GFR. Kidney Int. 2010;77:617-23.

31. Melamed ML, Horwitz EJ, Dobre MA, Abramowitz MK, Zhang L, Lo Y, et al. Effects of sodium bicarbonate in CKD stages 3 and 4: a randomized, placebo-controlled, multicenter clinical trial. Am J Kidney Dis. 2019. https:// doi.org/10.1053/j.ajkd.2019.07.016 [Epub ahead of print].

32. Di lorio B, Aucella F, Conte G, Cupisti A, Santoro D. A prospective, multicenter, randomized, controlled study: the correction of metabolic acidosis with use of bicarbonate in chronic renal insufficiency (UBI) study. J Nephrol. 2012;25:437-40
33. Gaggl M, Cejka D, Plischke $M$, Heinze G, Fraunschiel M, Schmidt A, et al. Effect of oral sodium bicarbonate supplementation on progression of chronic kidney disease in patients with chronic metabolic acidosis: study protocol for a randomized controlled trial (SoBic-Study). Trials. 2013:14:196.

34. Di lorio BR, Bellasi A, Raphael KL, Santoro D, Aucella F, Garofano L, et al. Treatment of metabolic acidosis with sodium bicarbonate delays progression of chronic kidney disease: the UBI Study. J Nephrol. 2019;32: 989-1001.

35. Wesson DE, Mathur $V$, Tangri $N$, Stasiv $Y$, Parsell D, Li E, et al. Veverimer versus placebo in patients with metabolic acidosis associated with chronic kidney disease: a multicentre, randomised, double-blind, controlled, phase 3 trial. Lancet. 2019;313:1417-27.

36. Wesson DE, Mathur V, Tangri N, Stasiv Y, Parsell D, Li E, et al. Long-term safety and efficacy of veverimer in patients with metabolic acidosis in chronic kidney disease: a multicentre, randomised, blinded, placebocontrolled, 40-week extension. Lancet. 2019;394(10196):396-406.

\section{Publisher's Note}

Springer Nature remains neutral with regard to jurisdictional claims in published maps and institutional affiliations.
Ready to submit your research? Choose BMC and benefit from:

- fast, convenient online submission

- thorough peer review by experienced researchers in your field

- rapid publication on acceptance

- support for research data, including large and complex data types

- gold Open Access which fosters wider collaboration and increased citations

- maximum visibility for your research: over $100 \mathrm{M}$ website views per year

At $\mathrm{BMC}$, research is always in progress.

Learn more biomedcentral.com/submissions 